\title{
Unusual intraosseous capillary hemangioma of the mandible
}

\author{
Omur Dereci ${ }^{1}$, Mustafa Fuat Acikalin ${ }^{2}$, Sinan $\mathrm{Ay}^{1}$
}

Correspondence: Dr. Omur Dereci

Email: odereci@ogu.edu.tr
'Department of Oral and Maxillofacial Surgery, Eskişehir Osmangazi University, Eskişehir, Turkiye, 'Department of Pathology, Eskişehir Osmangazi University, Eskişehir, Turkiye

\section{ABSTRACT \\ Intraosseous hemangioma is a benign vascular neoplasm, which is mostly seen in vertebrae, maxillofacial bones, and long bones. Intraosseous hemangioma is rarely seen on jaw bones compared to other skeletal bones and usually occurs in the cavernous form. Capillary intraosseous hemangioma of jaws is an uncommon form of intraosseous hemangioma and has not been thoroughly described so far. In this study, a case of capillary intraosseous hemangioma of the mandible was presented with relevant literature review.}

Key words: Capillary hemangioma, hemangioma, intraosseous, vascular malformation

\section{INTRODUCTION}

Hemangioma is a vascular malformation or neoplasm that originates from endothelial cells. Hemangiomas are generally classified into capillary, cavernous, mixed and sclerosing types according to the type of blood cells they are composed. ${ }^{[1,2]}$ Hemangiomas are mostly seen in the head and neck region and thought to originate from endothelial progenitor cells. ${ }^{[3]}$

Oral capillary hemangiomas consist small-sized, and thin walled capillary-like vessels, which are lined with a layer of endothelial cells and usually are localized on oral soft tissues. ${ }^{[1]}$ Clinically, capillary hemangiomas are soft, small-sized, lobulated, or solitary lesions with a color range between red and blue due to the profundity of the lesion. They tend to diminish in size after a proliferative postnatal phase. $^{[4]}$

Oral capillary hemangiomas are rarely seen in adults and mainly localized on oral mucosa or gingiva. ${ }^{[1,5]}$ The intraosseous form of capillary hemangioma is an uncommon entity and reported to be seen in the metacarpal, frontal, and temporal bones. ${ }^{[6-8]}$ In this report, an unusual case of intraosseous capillary hemangioma of the mandible was presented with radiological and histological features.

\section{CASE REPORT}

A 68-year-old female patient referred to our clinic for further examination of the radiolucent cyst-like lesion on her mandible. The clinical examination was normal, and the patient had no complaints regarding the lesion. The lesion was located on left canine-premolar region with sclerotic curly borders that is suggestive of a benign lesion [Figure 1]. The medical anamnesis was noncontributory. Computed tomography (CT) imaging was considered for further evaluation. The sclerotic boundaries of the lesion were prominently revealed on the axial CT section [Figure 2]. The patient was scheduled for surgical enucleation of the lesion.

Vertical and sulcular incisions were performed to expose the operation site. A direct approach to the lesion was provided with surgical burs with

This is an open access article distributed under the terms of the Creative Commons Attribution-NonCommercial-ShareAlike 3.0 License, which allows others to remix, tweak, and build upon the work non-commercially, as long as the author is credited and the new creations are licensed under the identical terms.

For reprints contact: reprints@medknow.com

How to cite this article: Dereci O, Acikalin MF, Ay S. Unusual intraosseous capillary hemangioma of the mandible. Eur $\mathrm{J}$ Dent 2015;9:438-41.

DOI: $10.4103 / 1305-7456.163236$ 
copious saline irrigation. Surgical curettage was performed with unexpected moderate bleeding of the lesion [Figure 3]. The surgical specimen has a solid structure with bluish-brown color [Figure 4]. A provisional diagnosis of central giant cell granuloma was made due to the intraoperative unexpected bleeding. Histological examination revealed numerous small-sized vessels that are consistent

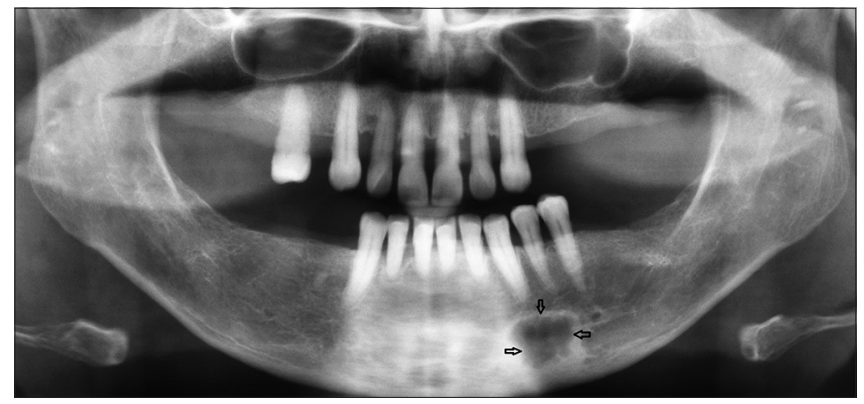

Figure 1: Panoramic radiography revealed radiolucent cyst-like lesion with irregular sclerotic borders localized at the mandibular canine-premolar region

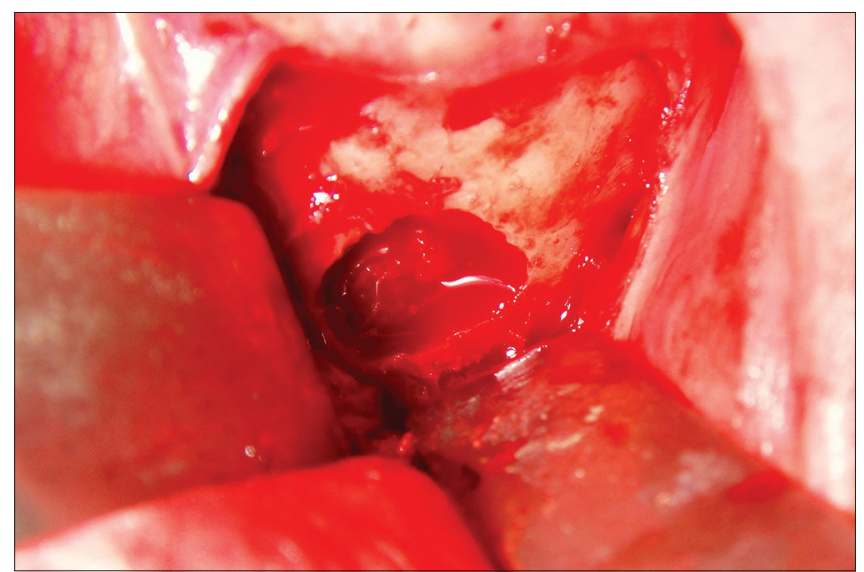

Figure 3: Intraoperative appearance of capillary hemangioma. Bleeding of the lesion can be clearly seen

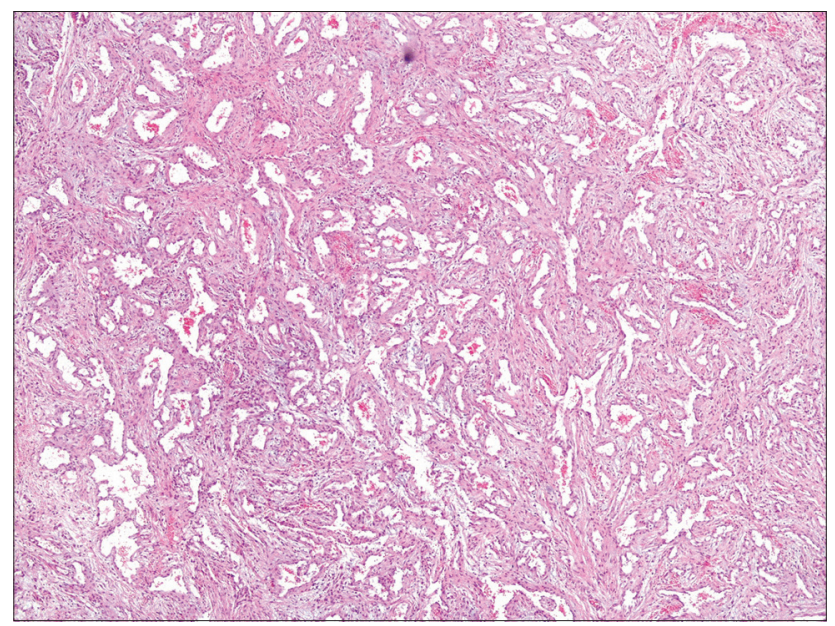

Figure 5: Capillary hemangioma consisting of proliferated, small-sized blood vessels $(\mathrm{HE} \times 40)$ with capillary vessels [Figure 5]. A single layer of endothelial lining was present in the proliferating capillary vessels [Figure6]. A diagnosis of intraosseous capillary hemangioma was made. The healing of the surgical site was uneventful at postoperative day 10 . The patient was undertaken in follow-up period with 3 months intervals.

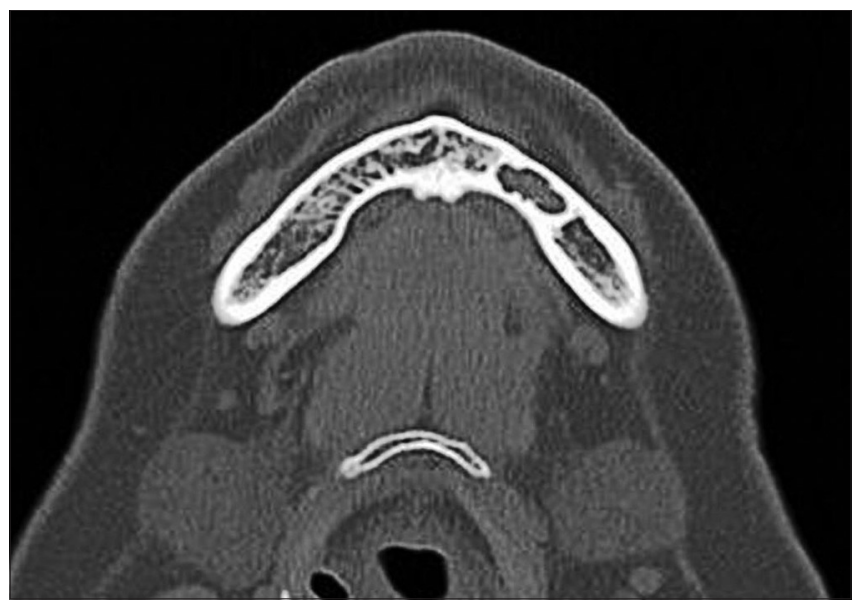

Figure 2: Axial computed tomography section reveals irregular, nonuniform sclerotic borders of the lesion

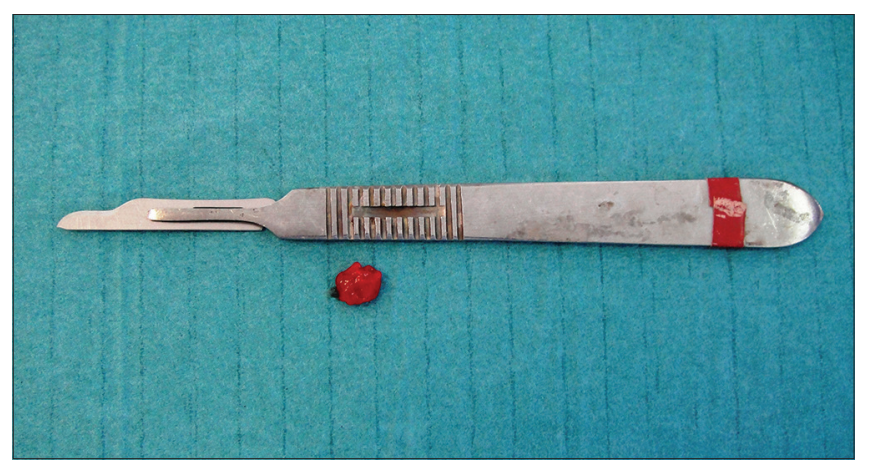

Figure 4: Postoperative appearance of the surgical specimen

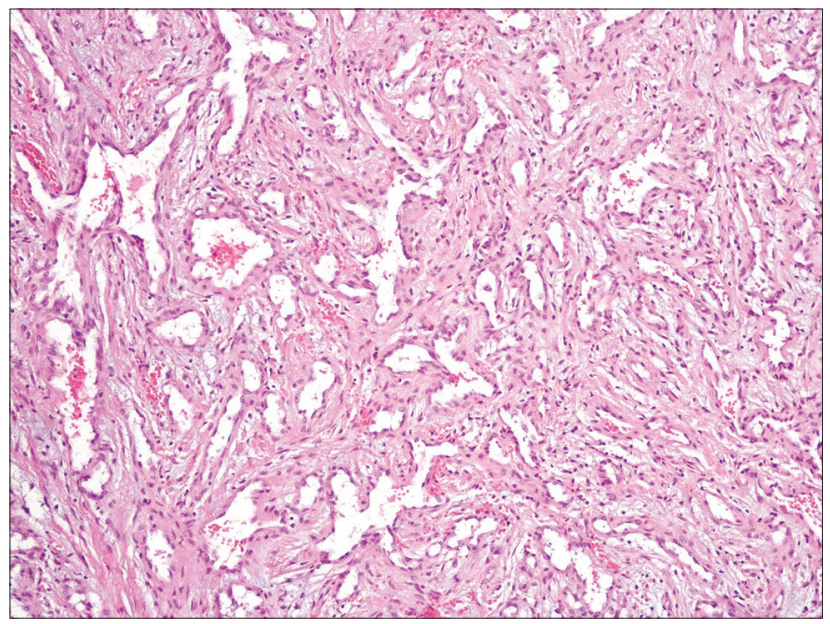

Figure 6: Proliferated blood vessels lined by a single layer of bland endothelial cells $(\mathrm{HE} \times 100)$ 


\section{DISCUSSION}

Intraosseous hemangiomas of the jaws are benign vasoformative neoplasms. They are asymptomatic and mostly discovered incidentally on plain radiographs. Intraosseous hemangiomas are commonly localized in calvaria and spine and affects long bones and other skeletal bones less frequently. ${ }^{[9]}$ Intraosseous hemangiomas of the jaws are mostly located on mandible with a female preponderance. ${ }^{[10]}$

Clinical presentation of intraosseous hemangioma is independent from the histological type. Most cases are asymptomatic. Several patients with intraosseous hemangioma experience pain and swelling. Paresthesia of the lips or mental region can be seen. ${ }^{[10]}$ Patients with high- pressure hemangiomas often report a sense of pulsation at the related region.

There are very few reported cases of intraosseous capillary hemangioma of the jaws. Perugini et al..$^{[1]}$ reported two cases of cellular hemangioma, which may correspond to capillary hemangioma on the mandible in their study according to a previously suggested classification system. Mutlu et al. ${ }^{[12]}$ reported a case of intraosseous capillary hemangioma in a newborn. Cavernous hemangioma is the most common type of intraosseous hemangioma of the jaws. ${ }^{[13]}$ Several cases of cavernous intraosseous hemangiomas of the jaws were reported with clinical and histopathological features. ${ }^{[10,12,14]}$

Skeletal intraosseous hemangiomas show a radiographic pattern of honeycombing and lace-like appearance. ${ }^{[6]}$ A preoperative arteriogram is recommended for screening of the supplying vascular structures and observation of soft tissue extension. CT imaging technique is valuable in the diagnosis of intraosseous hemangioma. ${ }^{[15,16]}$ Trabecular thickening and sclerotic punctate areas which are called polka-dots can be seen on CT examinations of skeletal intraosseous hemangiomas. Plain radiography and CT findings of intraosseous mandibular hemangiomas include unilocular radiolucency with sclerotic rims, resembling a jaw cyst or sunburst or honeycomb appearance radiating from central to the periphery with or without radiopaque areas. ${ }^{[14,15]}$ Capillary intraosseous hemangioma in the current report showed irregular, but well-defined borders in both panoramic radiography, and $\mathrm{CT}$ imaging which is consistent with reports of intraosseous mandibular cavernous hemangioma in the literature. ${ }^{[10,15]}$
Treatment of intraosseous hemangioma varies due to the extension and dimension of the lesion. If the lesion is asymptomatic or superficial and cause no esthetical problems, they can be left untreated. In general, surgical excision with or without preoperative embolization is suggested in the treatment of intraosseous or soft tissue hemangiomas. ${ }^{[11,14,17]}$ Radiotherapy and sclerotherapy are also used in the treatment. ${ }^{[5,14]}$ In the current case, the lesion was surgically treated with simple curettage. Preoperative embolization was not considered due to the small size and indolent radiographic appearance of the lesion.

Capillary intraosseous hemangioma of skeletal bones was reported several times. However, capillary hemangioma of the mandible has been an uncommon and undefined entity. To our knowledge, the present case is the fourth case reported in the literature. Radiographic findings of the lesion are similar with a cavernous form of intraosseous mandibular hemangioma. CT imaging of intraosseous hemangiomas enables the clinician to examine the borders and content of the lesion more carefully, and helps the surgeon to decide the treatment modality that is suitable for the current case.

\section{Financial support and sponsorship}

Nil.

\section{Conflicts of interest}

There are no conflicts of interest.

\section{REFERENCES}

1. Açikgöz A, Sakallioglu U, Ozdamar S, Uysal A. Rare benign tumours of oral cavity - Capillary haemangioma of palatal mucosa: A case report. Int J Paediatr Dent 2000;10:161-5.

2. Chin DC. Treatment of maxillary hemangioma with a sclerosing agent. Oral Surg Oral Med Oral Pathol 1983;55:247-9.

3. Eivazi B, Ardelean M, Bäumler W, Berlien HP, Cremer H, Elluru R, et al. Update on hemangiomas and vascular malformations of the head and neck. Eur Arch Otorhinolaryngol 2009;266:187-97.

4. Williams HJ, Wake MJ, John PR. Intraosseous haemangioma of the mandible: A case report. Pediatr Radiol 2002;32:605-8.

5. da Silva WB, Ribeiro AL, de Menezes SA, de Jesus Viana Pinheiro J, de Melo Alves-Junior S. Oral capillary hemangioma: A clinical protocol of diagnosis and treatment in adults. Oral Maxillofac Surg 2014;18:431-7.

6. Hung CT, Jou IM, Huang MT. Intraosseous capillary haemangioma of a metacarpal bone. J Hand Surg Eur Vol 2012;37:76-7.

7. Yang G, Li C, Chen X, Liu Y, Han D, Gao X, et al. Large capillary hemangioma of the temporal bone with a dural tail sign: A case report. Oncol Lett 2014;8:183-6.

8. Hook SR, Font RL, McCrary JA, Harper RL. Intraosseous capillary hemangioma of the frontal bone. Am J Ophthalmol 1987;103:824-7.

9. Murphey MD, Fairbairn KJ, Parman LM, Baxter KG, Parsa MB, Smith WS. From the archives of the AFIP. Musculoskeletal angiomatous lesions: Radiologic-pathologic correlation. Radiographics 1995;15:893-917.

10. Eliot CA, Castle JT. Intraosseous hemangioma of the anterior mandible. Head Neck Pathol 2010;4:123-5.

11. Perugini M, Renzi G, Gasparini G, Cerulli G, Becelli R. Intraosseous hemangioma of the maxillofacial district: Clinical analysis and surgical 
treatment in 10 consecutive patients. J Craniofac Surg 2004;15:980-5.

12. Mutlu M, Yaris N, Aslan Y, Kul S, Imamoglu M, Ersöz S. Intraosseous noninvoluting congenital hemangioma of the mandible in a neonate. Turk J Pediatr 2009;51:507-9.

13. Cheng NC, Lai DM, Hsie MH, Liao SL, Chen YB. Intraosseous hemangiomas of the facial bone. Plast Reconstr Surg 2006;117:2366-72.

14. Gómez Oliveira G, García-Rozado A, Luaces Rey R. Intraosseous mandibular hemangioma. A case report and review of the literature. Med Oral Patol Oral Cir Bucal 2008;13:E496-8.

15. Fernández LR, Luberti RF, Domínguez FV. Radiographic features of osseous hemangioma in the maxillo-facial region. Bibliographic review and case report. Med Oral 2003;8:166-77.

16. Karatas $\mathrm{OH}$, Toy E. Three-dimensional imaging techniques: A literature review. Eur J Dent 2014;8:132-40.
17. Akbulut N, Kursun ES, Tumer MK, Kamburoglu K, Gulsen U. Is the 810-nm diode laser the best choice in oral soft tissue therapy? Eur J Dent 2013;7:207-11.

\begin{tabular}{|l|l|}
\hline \multicolumn{2}{|c|}{ Access this article online } \\
\hline Quick Response Code: & \\
\hline
\end{tabular}

